IOSR Journal of Pharmacy

ISSN: 2250-3013, www.iosrphr.org

\||| Volume 2 Issue 5 \||| Sep-Oct. 2012 ||| PP.46-50

\title{
Development and validation of cleaning procedure of mixing equipment used for manufacturing ceftriaxone and Sulbactam injection tablet by using total organic carbon
}

\author{
Nirav Patel $^{* 1}$, Sneha Jansari ${ }^{2}$, Alpesh Arvadiya ${ }^{3}$, Kalpesh Panchal ${ }^{1}$, \\ Hemant Desai ${ }^{1}$
}

\begin{abstract}
This paper presents a useful method using total organic carbon analyzers employing combustion for validating equipment cleaning procedures and verifying cleaning in a pharmaceutical plant. The study summarizes the initial steps that should be taken into account and focuses particularly on the solutions to some of the most critical considerations (e.g., detection and quantification limits, recovery). Also described are the calculation limits and the good results obtained. Cleaning validation is the process of assuring that cleaning procedures effectively remove the residue from manufacturing equipment/facilities below a predetermined level. This is necessary to assure the quality of future products using the equipment, to prevent cross-contamination, and as a World Health Organization Good Manufacturing Practices requirement. We have applied the Total Organic Carbon (TOC) analysis method to a number of pharmaceutical products. In this article we discuss the TOC method that we developed for measuring residual of sulbactam and ceftriaxone injection contain sulbactam (500mg) and ceftriaxone (1000mg) on surface of mixing tank during manufacturing process. Sulbactam contain 37.61\%carbon and ceftriaxone contain $32.64 \%$ carbon The method with correlation coefficient $R^{2}=0.998$ and method offers low detection capability (0.01ppm) and rapid sample analysis time. The accurate recovery values ranged from $96.46 \pm 1.92$ with method precision less than 2\%RSD of precision. We found that the TOC method is applicable for determining residual of sulbactam and ceftriaxone on pharmaceutical equipment surfaces and will be useful for cleaning validation.
\end{abstract}

Keywords-Ceftriaxone, equipment surface (mixing tank), injection, sulbactam, Total Organic Carbon

\section{INTRODUCTION}

Cleaning is one of the critical processes in pharmaceutical manufacturing. Equipment contamination may come from any of the materials that have been in contact with the equipment surfaces. It is critical to avoid carryover of trace amounts of either active or other materials from one batch to another in order to avoid crosscontamination of the subsequent product. For that reason, equipment used in pharmaceutical manufacturing must be cleaned meticulously ${ }^{[1,2]}$, and the cleaning procedure used must be validated ${ }^{[3-5]}$. In the pharmaceutical industry, Good Manufacturing Practices (GMP) require that the cleaning of drug manufacturing equipment be validated $^{[6]}$. Many different validation techniques can demonstrate that the manufacturing equipment is cleaned and essentially free from residual active drug substances and all cleaning agents. Common analytical techniques in the validation process include HPLC, spectrophotometry (UV/Vis) and TOC. HPLC and UV/Vis are classified as specific methods that identify and measure appropriate active and substances. TOC is classified as a non-specific method and is ideal for detecting all carbon-containing compounds, including active species, excipients, and cleaning agent(s). The disadvantage of specific methods, particularly HLPC, is that a new procedure must be developed for every active drug substance that is manufactured. This development process can be very time consuming and tedious, plus important sampling issues also must be considered. In addition, HPLC analyses must be performed in a relatively short time period after sampling to avoid any chemical deterioration of the active substance. Finally, the sensitivity of HPLC methods can be limited by the presence of degradation products. TOC analysis can be adapted to any drug compound or cleaning agent that contains carbon. The method is sensitive to the ppb range and is less time consuming than HPLC or UV/Vis. USP TOC methods are standard for Water for Injection and Purified Water ${ }^{[7]}$, and simple modifications of these methods can be used for cleaning validation. ${ }^{[8]}$, Ceftriaxone is (6R,7R)-3[(acetyl-oxy)methyl]-7-[[2Z)-2amino-4thiazolyl)(methoxy amino)-acetyl]amino]-8-oxo-5-thia-1-azabicyclo[4,2,0]oct-2-ene-2carboxylic acid[9] having molecular formula $\mathrm{C}_{18} \mathrm{H}_{18} \mathrm{~N}_{8} \mathrm{O}_{7} \mathrm{~S}_{3}$ and molecular weight 661.6 and Sulbactam is chemically (2R,5R)-3,3dimethyl-4,47-trioxo-4,6thia-1-azabicyclo[3-2-0] heptane-2-carboxylic acid $^{[10]}$ having molecular formula $\mathrm{C}_{8} \mathrm{H}_{10} \mathrm{NNaO}_{5} \mathrm{~S}$ and molecular weight 255.22 


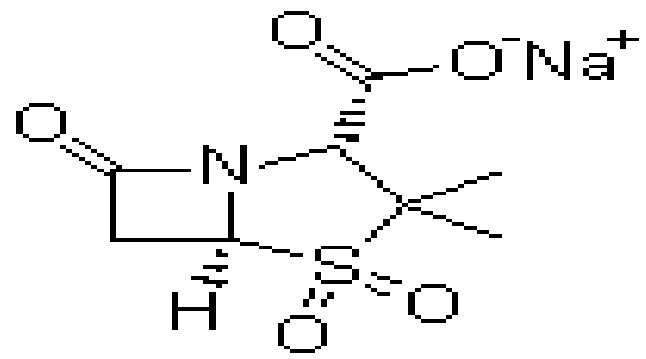

Figure 1: structure of sulbactam sodium

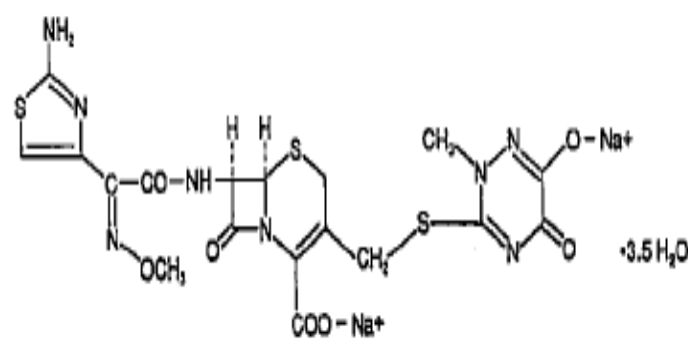

Figure 2: structure of ceftriaxone sodium

\subsection{Material}

\section{MATERIAL AND METHODS}

In this study we were used $\mathrm{HCl}$, USP Sucrose,USP 1,4-benzoquinone (Finar Reagent, Ahemdabad, India),sulbactam and ceftriaxone injection sample from Nirlife Healthcare, Texwipe alpha swab polyester (Baxter scientific product,McGaw Park,IL), Water with less TOC ( $25 \mathrm{ppb})$ as cleaning agent

\subsection{Equipment}

TOC analyzer used in this study was a TOC-5000(Shimadzu, Columbia, MD) equipped with 74position autosampler, TOC-5000 used acidification of sample by $\mathrm{HCl}$ by sparing with purified air to remove inorganic carbon as $\mathrm{CO}_{2}$ gas And organic carbon remain in the solution which is oxidized to $\mathrm{CO}_{2}$ gas in combustion tube with catalyst at $680{ }^{\circ} \mathrm{C}$ and Mettler Toledo analytical balance (Germany) for weighing purpose

\subsection{Toc System Suitability Test}

\section{EXPERIMENTAL WORK}

The TOC system suitability test described in the USP indicates the use of 2 types of USP reference standards (Sucrose and 1,4-benzoquinone). Sucrose is used as the standard reagent solution, and 1,4benzoquinone is used as the system suitability test solution. As for calibration of the TOC analyzer, a suitable method is described for the particular instrument. The test procedure is as Water is measure the TOC in pure water (pure water used for preparing test solution) and take this value as rw, Sucrose is measure the TOC in sucrose standard solution make by dissolving $0.1163 \mathrm{~g}$ sucrose in $1 \mathrm{~L}$ purified water $(50000 \mathrm{ppb}$ of $\mathrm{C}$ ) and make a dilution into $1 \mathrm{~L}$ volumetric flask to get carbon concentration $500 \mathrm{ppb}$ and take value as rs, 1,4-benzoquinone is measure the TOC in system suitability test solution (1,4-benzoquinone solution make by dissolving $0.08 \mathrm{~g}$ into1L purified water $(50000 \mathrm{ppb}$ of $\mathrm{C}$ ) and dilution into $1 \mathrm{~L}$ volumetric flask with purified water to get carbon concentration $500 \mathrm{ppb}$ and take value as rss, and test result was shown in (Table 1). If system suitability test solution detection rate $=100(\mathrm{rss}-\mathrm{rw}) /(\mathrm{rs}-\mathrm{rw})$ is $85 \%-115 \%$, system suitability test requirement is satisfied $^{[11]}$

\subsection{Linearity}

For cleaning validation of sulbactam and ceftriaxone injection(NIRIXONE-S $1.5 \mathrm{~g}$ ) in mixing tank by TOC, we require the linearity of final product (injection) NIRIXONE-S sample, make a solution of final product by taking $1.5 \mathrm{~g}$ final product in one $1000 \mathrm{ml}$ volumetric flask with purified water and then take $1 \mathrm{ml}$ of this solution in $150 \mathrm{ml}$ volumetric flask with purified water and make a dilution of 1,3,5,7,9 ppm in series of $10 \mathrm{ml}$ volumetric flask and measure this sample in TOC in set of three,the linearity excel graph shown in( fig. 3) and linearity in (Table 2) 


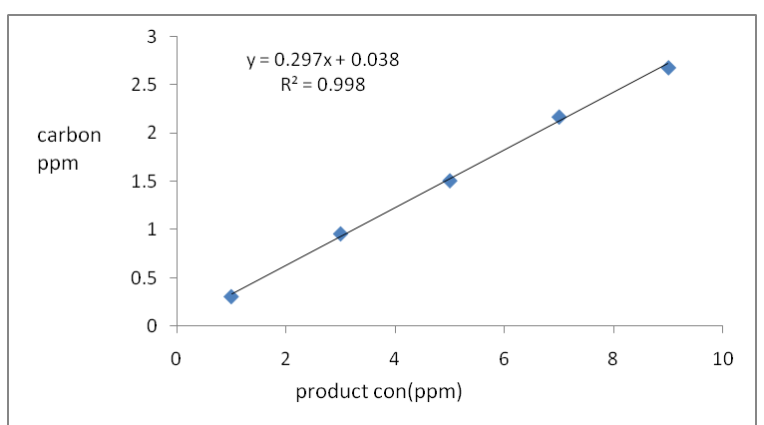

Figure 3: linearity of final product

Table 2: linearity of product

\begin{tabular}{|l|l|}
\hline $\begin{array}{l}\text { Concentration } \\
(\mathrm{ppm})\end{array}$ & $\begin{array}{l}\text { Carbon } \\
(\mathrm{ppm})\end{array}$ \\
\hline 1 & 0.31 \\
\hline 3 & 0.96 \\
\hline 5 & 1.51 \\
\hline 7 & 2.17 \\
\hline 9 & 2.68 \\
\hline
\end{tabular}

\subsection{Limit Of Detection And Quantization}

Limit of detection and quantization was measure by standard deviation method as par the guideline of ICH Q2B : Validation of Analytical Procedure[12].shown in(Table 3)

Table 3: Limit of Detection and Limit of Quantitation

\begin{tabular}{|l|l|}
\hline Parameter & Carbon(ppm) \\
\hline Limit of Detection & 0.01 \\
\hline Limit of Quantitation & 0.032 \\
\hline
\end{tabular}

\subsection{Accuracy and Precision}

To demonstrate accuracy and precision a one standard sample solution of final product like $3 \mathrm{ppm}$ as carbon was analyzed by TOC for ten time ${ }^{[12]}$ and result of accuracy and precision was shown in (Table 4)

Table 4: Precision and accuracy (\% recovery)

\begin{tabular}{|l|l|}
\hline Vial no. & Carbon(ppm) \\
\hline 1 & 0.96 \\
\hline 2 & 0.95 \\
\hline 3 & 0.93 \\
\hline 4 & 0.92 \\
\hline 5 & 0.98 \\
\hline 6 & 0.94 \\
\hline 7 & 0.97 \\
\hline 8 & 0.94 \\
\hline 9 & 0.95 \\
\hline 10 & 0.96 \\
\hline Average & 0.95 \\
\hline SD & 0.018 \\
\hline \%RSD & 1.92 \\
\hline \%Recovery & 96.46 \\
\hline
\end{tabular}

\subsection{Swab Recovery}

Stainless steel plates were used in the swab recovery test to simulate manufacturing equipment. One side of each plate was spiked with a solution of active substance $1.51 \mathrm{ppm}$ of $\mathrm{C}$. the plates were allowed to dry completely overnight at room temperature. A Texwipe alpha swab was moistened with low TOC $(<25 \mathrm{ppb})$ water and the spiked plate surface was swabbed both vertically and horizontally. The swab end was cut off, placed into a vial to which we added 50-mL of low TOC water. The vial was capped tight, vortexed, and allowed to stand for one hour prior to analysis. The same volume of each solution that was spiked onto the 
plates was separately spiked directly into $50-\mathrm{mL}$ of low TOC water and analyzed. The percent recoveries of substances are listed in (Table 5) Reported values are the average of three individual swab samples for each substance. The swab recoveries varied between $98.67 \%-100.66 \%$

Table 5: Swab Recovery (Residual Recovery)

\begin{tabular}{|l|l|}
\hline Substance & Linezolid \\
\hline $\begin{array}{l}\text { ppm of C spikedStandard } \\
\text { solution }\end{array}$ & 1.51 \\
\hline ppm of C spiked on Plate & 1.5 \\
\hline \%Recovery & 99.55 \\
\hline \%RD & 1.28 \\
\hline
\end{tabular}

\subsection{Application of This Developed Method To Process}

This method was apply on the cleaning process of mixing tank where sulbactam and ceftriaxone were mixed. injection is NIRIXONE-S contain Sulbactam (500mg) and Ceftriaxone(1000mg). For applying this method select sampling place in mixing tank(bottom site) having area $10 \mathrm{~cm}^{2}$ and swab it by using Texwipe alpha swab was moistened with low TOC $(<25 \mathrm{ppb})$ water and the spiked plate surface was swabbed both vertically and horizontally. The swab end was cut off, placed into a vial to which we added 50-mL of low TOC water. The vial was capped tight, vortexed, and allowed to stand for one hour prior to analysis. The same volume of each solution that was spiked onto the plates was separately spiked directly into 50-mL of low TOC water and analyzed by TOC (fig. 4) and result was in (Table 6)

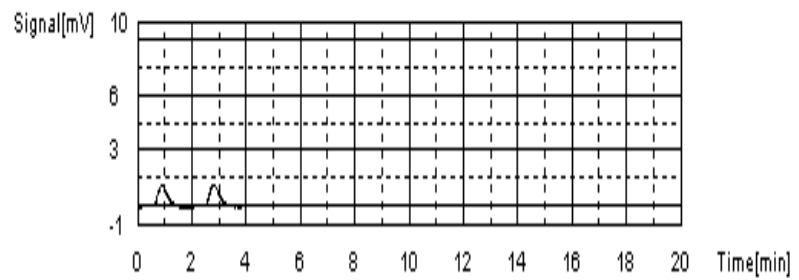

Figure 4: Toc graph of cleaning process sample of final product

Table 6: analysis of cleaning process sample

\begin{tabular}{|l|l|l|}
\hline Test & $\begin{array}{l}\text { Result } \\
\text { (Active Drug } \\
\text { substance in } \\
\text { ppm) }\end{array}$ & $\begin{array}{l}\text { Complies } \\
\text { with USP } \\
\text { limit } \\
\text { (Less than 10 } \\
\text { ppm) }\end{array}$ \\
\hline $\begin{array}{l}\text { cleaning process } \\
\text { sample }\end{array}$ & 2.18 & Yes \\
\hline $\begin{array}{l}\text { Individual (Sulbactam } \\
500 \text { mg) }\end{array}$ & 0.72 & Yes \\
\hline $\begin{array}{l}\text { Individual(Ceftriaxone } \\
1000 \mathrm{mg})\end{array}$ & 1.45 & Yes \\
\hline
\end{tabular}

\section{RESULT AND DISCUSSION}

From this study we measure the TOC and concentration of residual substance with linear Correlation Coefficient which is 0.998 and Residual recovery(Swab recovery) ranged between $98.67 \%-100.66 \%$ and lower detection limit was $0.01 \mathrm{ppm}$ found and \%RSD less than 2 for method precision and method also apply to cleaning process where we found $2.18 \mathrm{ppm}$ concentration of active drug substance (sulbactam $0.81 \mathrm{ppm}$ and ceftriaxone $0.71 \mathrm{ppm}$ ) which is complies USP limit(less than 10ppm) for cleaning validation. all this indicate the accuracy and precision of proposed methods

\section{CONCLUSION}

This study demonstrates that the TOC method is suitable for measuring organic residues on stainless steel surfaces for cleaning validation, and that it is a reliable tool for cleanin validation. The TOC method offers low limits of detection, excellent linearity, precision, and accuracy. All of these TOC results indicate that TOC technology a low cost, simple and less time consuming alternative for cleaning validation 


\section{ACKNOWLEDGEMENT}

The authors are thankful to Nirlife HealthCare, Ahmadabad.

\section{REFERENCES}

[1]. European Commission. Working Party on Control of Medicines and Inspections. Annex 15 to the EU Guide to Good Manufacturing Practice. Qualificationand Validation. European Commission: Brussels, 2001. http://ec.europa.eu/enterprise/pharmaceuticals/eudralex/vol-4/pdfs-en/v4an15.pdf. Accessed December 5, 2007.

[2]. Office of Regulatory Affairs, FDA. Guide to Inspections Validation of Cleaning Processes. www.fda.gov/ora/inspect_ref/igs/valid.html. Accessed December 5, 2005.

[3]. Salazar, R. Validación Industrial. In Su Aplicación a la Industria Farmacéutica y Afines, 1st ed., Romagraf: Barcelona, Spain, 1999; pp $386-414$.

[4]. Center for Drug Evaluation and Research, FDA.Can Total Organic Carbon (TOC) be an acceptable method for detecting residues of contaminants in evaluating cleaning effectiveness? Questions and Answers on Current Good Manufacturing Practices, Good Guidance Practices, Level 2 Guidance; Equipment. http://www.fda.gov/cder/guidance/cGMPs/equipment.htm\#TOC. Accessed 11/06/05.

[5]. LeBlanc, D. A. Equipment Cleaning. Encyclopaedia of Pharmaceutical Technology; 3rd ed.; Informa Healthcare USA, Inc.: New York, 2006; pp $1580-1592$.

[6]. Food and Drug Administration's Current Good Manufacturing Practice Regulations; 21 CFR 211.220

[7]. USP 23 Fifth Supplement; November 15, 1996

[8]. Total Organic Carbon Analysis for Cleaning Validation in Pharmaceutical Manufacturing, Anatel,2,December 1999

[9]. The United States Pharmacopoeia, 30th Revision, U.S. Pharmacopoeial Convention,Inc., Rockville, MD. 2007.

[10]. United States Pharmacopoeia,USP30-NF25, United States Pharmacopoeial Convention 2007, 257

[11]. ICH Topic Q 2 (R1) Validation of Analytical Procedures:Text and Methodology, European medicine Agency, June 1995 